\title{
INELASTIC DEMAND SPECTRA FOR BI-LINEAR SEISMIC ISOLATION SYSTEMS BASED ON NONLINEAR TIME HISTORY ANALYSES AND THE RESPONSE OF LEAD-RUBBER BEARING ISOLATION SYSTEMS SUBJECTED TO NEAR-SOURCE GROUND MOTIONS
}

\author{
John X Zhao ${ }^{1}$ and Jian Zhang ${ }^{1}$
}

\begin{abstract}
SUMMARY
In this study, we present an inelastic demand spectrum for the design of seismically-isolated structures using lead-rubber bearings or other types of isolators with bi-linear hysteresis loops and the inelastic spectrum can be used in the design of seismically-isolated structures in a very similar manner to capacity spectrum method. The inelastic demand spectrum is a very useful design tool for visual selection of optimal isolation parameters, and eliminates the use of equivalent linear-elastic substitute structures as the displacement demand is obtained from nonlinear time history analysis. The responses of seismically-isolated structures subjected to near-source ground motions with either large forward-directivity pulses or fault-fling pulses are presented. Our analyses suggest that seismic isolation can be used to protect structures subjected to recorded ground motions currently available to us, with acceptable levels of base shear coefficient and isolator displacement, except for one component of the TCU068 record from the 1999 Chichi, Taiwan, earthquake (which contained a large permanent displacement of nearly $10 \mathrm{~m}$ ).
\end{abstract}

Key words: inelastic demand spectra, capacity spectra, seismic isolation, lead-rubber bearings

\section{INTRODUCTION}

Seismic isolation has been used to protect structures from severe earthquake attack in many countries and is well accepted as an effective means to enable continuous use of the structure during and immediately after severe ground shaking.

In current design practices for seismically-isolated structures, an equivalent linear elastic structure with an effective period and an equivalent viscous damping ratio accounting for energy dissipation due to inelastic deformation of isolators is usually used for preliminary design. Subsequent time-domain nonlinear modelling for some, but not all, types of seismicallyisolated structures may be required (AASHTO 1991 and 1999 [1]).

In the light of large displacement demands of near-source records from the 1992 Landers earthquake, the 1994 Northridge earthquake and the 1995 Kobe earthquake, the performance of seismically-isolated structures under the excitation of near-source ground motions has been examined (Hall et al [2]). The near-source records from the 1999 Izmit, Turkey, and the 1999 Chichi, Taiwan, earthquake show very large displacement demands at long periods due to the faultfling effect (Abrahamson [3]), while the displacement demand in the short and intermediate periods is relatively moderate.
These observations further question the appropriateness of seismic isolation and alternative seismic isolation system using advanced seimi-active MR dampers was proposed (Ramallo et al [4]).

Simplified models for seismically-isolated structures with linear rubber bearing, lead-rubber bearing, friction pendulum and EDF isolation systems were used to assess the response of seismically-isolated structures subjected to near-source ground motions (Jangid and Kelly [5]). Appropriateness of nearsource factors of the 1997 UBC code for the design of seismically-isolated structures has been thoroughly investigated (Naeim and Kelly [6]).

In this study we will present an inelastic demand spectrum formulation, based on nonlinear time history analyses, for the design of seismically-isolated structures as an excellent design tool, eliminating the need for an equivalent linear-elastic substitute structure. The inelastic demand spectra are presented for a lead-rubber bearing or other isolation system with a post-yield stiffness ratio of about $10 \%$. We also present the inelastic demand spectra for near-source records with either forward-directivity or fault-fling pulses in order to discuss the appropriateness of seismic isolation for, and the response of seismically-isolated structures to, near-source records.

\footnotetext{
${ }^{1}$ GNS Science 1, Fairway Drive, Avalon, Lower Hutt, New Zealand (Member).
} 
The design detail of a seismically isolated structure will not be discussed, and design methodology and examples can be found from Naeim and Kelly [6] and the design manual by Kelly [7]. We presented the demand spectra for near-source records with the displacement demands similar to those of maximum considered earthquake (MCE) for most applications in New Zealand. However, if an isolation system designed to have the best performance (high equivalent damping ratio) for the MCE ground motion often has relative poor response in the ground shaking with a 475 year return period (see Figure 13, Zhao [8] - structure with extra dampers, Trevor Kelly, 2006, review comments). From this point of view, the optimal design choice derived from near-source records reported here may not lead to the best overall performance for a 475 year ground motion and $\mathrm{MCE}$ ground motions.

\section{INELASTIC DEMAND SPECTRA OF BI- LINEAR MODEL FOR SEISMIC ISOLATION SYSTEM}

For a single degree of freedom (SDF) structure with mass $m$, and damping coefficient $c$, under excitation of ground acceleration $\ddot{u}_{g}$, the displacement $x$ relative to the ground can be solved from

$$
m \ddot{x}+c \dot{x}+F(x)=-m \ddot{u}_{g}
$$

where $F(x)$ is the force developed in the structure and is the force developed in the isolator for the case of seismicallyisolated structures. For a given bi-linear model used in the design of a seismic isolation system, three parameters, the initial elastic stiffness, $K_{e}$, the post-yield stiffness, $K_{y}$ and $\alpha=$ $Q_{c} / W$, where $Q_{c}$ is the characteristic strength (the force at zero displacement in a hysteresis loop see Figure 1), and $W$ is the weight of the structure, can be used to define the model. The ratio of post-yield stiffness to initial stiffness, $\beta=K_{y} / K_{e}$, varies within a small range, $0.08-0.12$ for lead-rubber bearings (LRBs).

When the peak displacement, $D$, of a bilinear model is larger than the yield displacement, $D_{y}$, the lateral shear force, $F$, and the effective stiffness, $K_{\text {eff }}$ (secant stiffness) at peak displacement are given by

$$
\begin{aligned}
& F=Q_{c}+K_{y} D \\
& K_{\text {eff }}=K_{y}+Q_{c} / D
\end{aligned}
$$

Displacement $D_{N}=Q_{c} / K_{y}$ can be used to define a displacement index $\gamma=D / D_{N}$, and the spectral acceleration, i.e., the peak acceleration of the isolator can be found from,

$$
\begin{aligned}
& S A=\alpha(1+\gamma) g \\
& S A=\left(2 \pi / T_{\text {eff }}\right)^{2} D_{\max }
\end{aligned}
$$

Equation (3) is the relationship between the pseudoacceleration and peak displacement denoted by $D_{\max }$ which is calculated from nonlinear analysis and referred to as the spectral displacement at effective period $T_{\text {eff }}$ in this study. The effective period, $T_{\text {eff }}$, and the post yield period, $T_{y}$, are given by

$$
\begin{aligned}
& T_{e f f}=T_{y} \sqrt{\gamma /(1+\gamma)} \\
& T_{y}=2 \pi \sqrt{W / K_{y} g}
\end{aligned}
$$

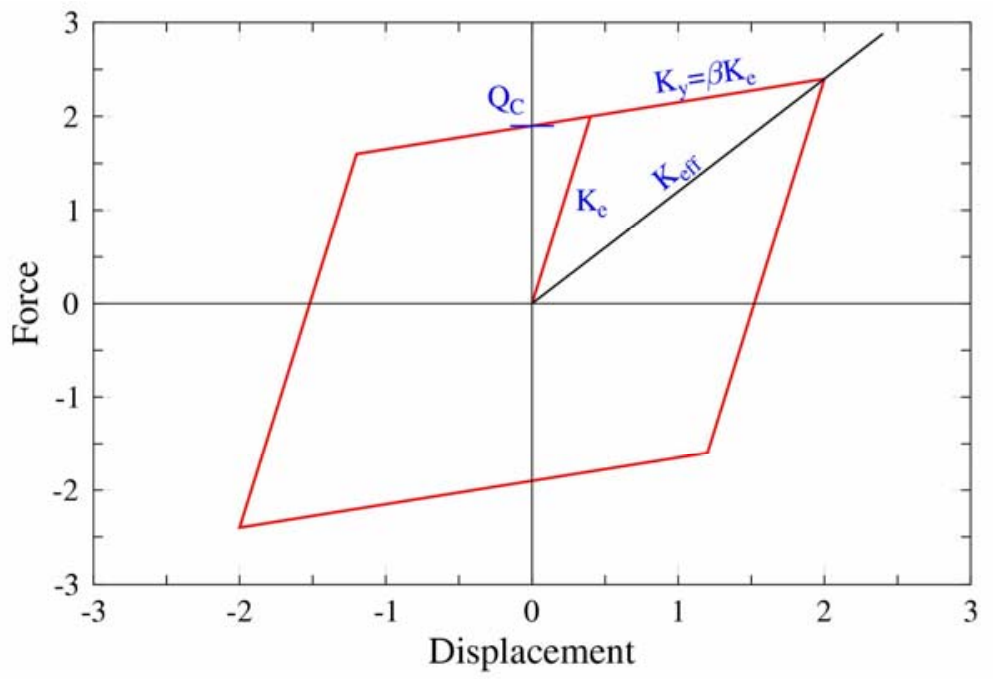

Figure 1. Parameters for a bi-linear model

Equation (3) is actually valid for any nonlinear system when there is no strength degradation, provided that $D_{\max }$ has been calculated for the actual nonlinear force-displacement model. It is accurate when there is no viscous damping, and approximate when the viscous damping is non zero. For an isolation system such as the lead-rubber bearing system, the post-yield stiffness is about $10 \%$ of the initial stiffness, and Equation (3) is then reasonably accurate for a constant viscous damping coefficient if the damping ratio is $5 \%$ or less.
Note that displacement $D_{N}=Q_{c} / K_{y}$ is a convenient mathematical variable for Equations (3a) and (4a). For lead rubber bearings, characteristic strength $Q_{c}$ is the lead shear force and post yield stiffness $K_{y}$ is the rubber bearing stiffness without lead cores. Both parameters are specified and controlled during design and manufacturing process though $D_{N}$ is not used in current design practice.

For a seismic isolation system using lead-rubber bearings, energy dissipation is through the plastic deformation of lead plugs, in a hysteretic manner, because the amount of energy 
dissipated in a displacement cycle is largely independent of loading speed (Skinner et al, 1993, Chapter 3) and linearly depends on the isolator displacement (Naeim and Kelly [6], Chapter 5). For a friction device, the energy dissipation also is hysteretic rather than viscous, though the friction coefficient can be velocity dependent. The assumption of 5\% viscous damping is likely to be inherited from the design of conventional structures, but is seldom supported by experimental data. Seismically isolated structures usually have clear seismic gaps, and so any additional energy dissipation through movement of structural and nonstructural elements should be small. For friction isolation systems with very large initial stiffnesses, an assumption of $5 \%$ viscous damping ratio calculated from initial stiffness could lead to an under-estimate of isolator response. Alternatively, a viscous damping ratio of $5 \%$ calculated from the post yield stiffness could be more appropriate if viscous damping has to be used. Another reasonable alternative is to assume that the damping ratio of $5 \%$ is constant in both the elastic phase and the post-yield phase. This assumption means that the damping coefficient in Equation 1 can be calculated by

$$
\begin{gathered}
c=2 \xi m \omega_{T} \\
\omega_{T}=\sqrt{\frac{K_{T}}{m}}
\end{gathered}
$$

where $\mathrm{m}$ is the mass of the structure and $\omega_{\mathrm{T}}$ calculated from the instantaneous tangent stiffness $K_{T}$ of the isolator and $\xi$ is the viscous damping ratio. Using either constant damping ratio of $5 \%$ calculated from post yield stiffness or $\xi=5 \%$ for both elastic and yield phases, the accuracy of Equation (3) is improved for lead-rubber bearing systems (see Figure 2 and the comments at the end of this section). For friction isolation systems which has relatively large initial stiffness compared with the post yield stiffness, a constant damping ratio of 5\% for both elastic and post-yield phase or a constant damping ratio of $5 \%$ calculated from the post yield stiffness will have to be used. For the results presented in this study, a tangent stiffness dependent damping coefficient has been used.

The equivalent damping ratio for a bi-linear system at a displacement $S D$ can be defined as:

$$
\begin{aligned}
& \xi_{\text {eff }}=\frac{2}{\pi(1+\gamma)}\left(1-\frac{\gamma_{y}}{\gamma}\right) \\
& \gamma_{y} \equiv \frac{D_{Y}}{D_{N}}=\frac{\beta}{1-\beta}
\end{aligned}
$$

where $D_{y}$ is the yielding displacement of the isolator.

For any given equivalent damping ratio, two real values of $\gamma$ can be obtained:

$$
\gamma_{1,2}=\frac{1}{\pi \xi_{\text {eff }}}-\frac{1}{2} \pm \sqrt{\left(\frac{1}{\pi \xi_{\text {eff }}}-\frac{1}{2}\right)^{2}-\frac{2 \beta}{\pi \xi_{\text {eff }}(1-\beta)}}
$$
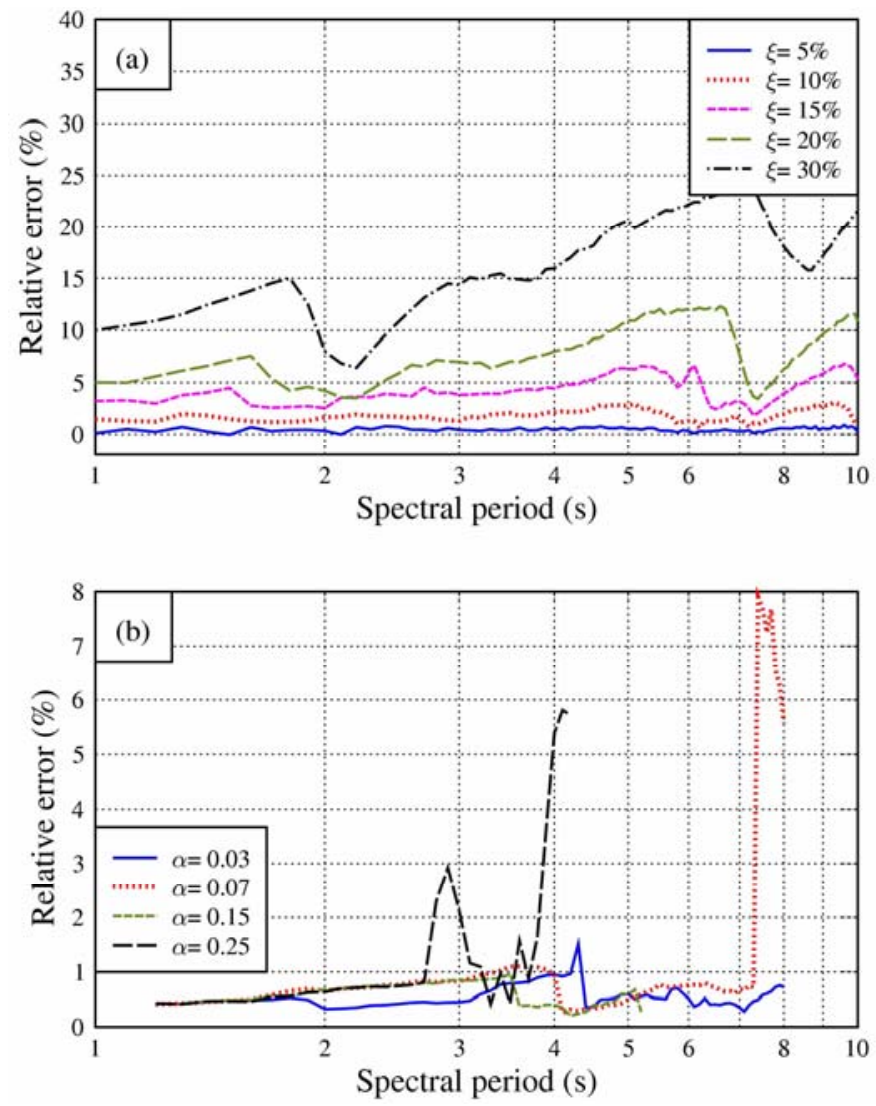

Figure 2. Relative errors associated with pseudo-acceleration assumption, (a) errors for elastic single-degree-freedom structure, and (b) error for a bi-linear structure with 5\% viscous damping ratio and tangent stiffness dependent damping coefficient (Equation 1) with $\alpha=Q_{c} / W$. Note that the sudden increase of error in (b) is at a small isolator displacement that is unlikely to be used in real structures. 
The two values of $\gamma$ define the boundaries within which the equivalent damping ratios will be larger than or equal to $\xi_{\text {eff. }}$. Note that $\xi_{\text {eff }}$ is not required or explicitly used in the calculation of inelastic demand spectra. The graphic form of Equation (6a) is presented by Naeim and Kelly [6] and by Zhao [8] (Figure 5) using ductility ratios.

The initial elastic period $\mathrm{T}_{\mathrm{e}}$ and post-yield period $\mathrm{T}_{\mathrm{y}}$ are related by

$$
\begin{aligned}
& T_{e}=T_{y} \sqrt{\beta} \\
& T_{y}=T_{e f f} / \sqrt{1-\frac{\alpha g T_{e f f}^{2}}{4 \pi^{2} D_{\max }}}
\end{aligned}
$$

For a seismic isolation system, the UBC 1997 code (1997) [9] and the AASHTO 1991 and 1999 codes [1] require the system to provide enough restoring force that the permanent displacement after a design ground motion earthquake is not too large to accommodate the displacement required by any possible aftershock. The restoring force requirement is given by

$$
F\left(D_{\max }\right)-F\left(0.5 D_{\max }\right) \geq \eta W
$$

where $F$ is the base shear as a function of peak displacement $D_{\max }$, and $\eta=0.025$ is specified in the UBC 1997 code [9]. An alternative form of Equation (9) can be written as

$$
\gamma \geq \gamma_{R F}=\frac{2 \eta}{\alpha}
$$

$$
S A \geq \alpha\left(1+\gamma_{R F}\right) g
$$

By using the displacement index, $\gamma$, the base shear coefficient, the equivalent damping ratios and the restoring force requirement can be conveniently displayed on a single plot which provides an excellent means for visual selection of an appropriate system.

When a substitute elastic structure is used in a design process (1997 UBC [9]), the pseudo-acceleration is used as the measure of total acceleration (total acceleration is used to calculated for base shear for the upper structure in the design of seismic isolation). This assumption can result in considerably large error. Figure $2 \mathrm{a}$ shows the relative error (the difference between total and pseudo-acceleration divided by the total acceleration) for the TCU068 record (EW component) from the 1999 Chichi Taiwan earthquake. At long periods for a damping ratio of $20-30 \%$ the relative error is up to $20-25 \%$ (also see Jangid and Kelly [5]). In additional to the errors associated with the pseudo-acceleration assumption, using an equivalent linear elastic structure to model a bi-linear system introduces further errors to the estimates of structural response. For a bi-linear system, energy dissipation is from the inelastic deformation, and the viscous damping ratio accounting for any additional energy dissipation should be small (for example, $5 \%$ or less). The error from the pseudo-spectrum assumption for $\beta=0.1$ with a viscous damping ratio of 5\% (damping coefficient dependent on the tangent stiffness) is small, up to $8 \%$ for the TCU068 record, shown in Figure 2b. Our results show that the error rapidly increases from $1 \%$ to over $3 \%$ only when the isolator displacement amplitude is of a similar order to the yield displacement, which is very unlikely to occur in response to typical design ground motions. Note that supplemented viscous damping used together with a bilinearisolation system cannot be accounted for in calculating the inelastic demand spectra.

\section{AN EXAMPLE OF INELASTIC DEMAND SPECTRA FOR MODERATELY STRONG AND STRONG GROUND MOTIONS}

Inelastic demand spectra are presented for two strong motion records, the NS component of the 1940 El Centro record, which has only a moderately large displacement demand, and the fault-normal component of the Lucerne record (1992 Landers earthquake), which has a very large displacement demand at long periods.

The purpose of the present study is to improve the design of LRB seismic isolation systems and so we limit our scope to post-yield stiffness ratio $\beta=0.1$ which is valid for a large number of LRB types. The generation of inelastic spectra presented is quite simple:

1) Select a value of $\alpha=Q c / W$ and an effective periods;

2) Assume the peak displacement and calculated the elastic period $T_{e}$ and $T_{y}$ from Equation 8;

3) Carry out nonlinear time-domain analysis to compute the peak displacement; and

4) Check if the computed displacement in step 3 is close to the value used in step 2. If the difference is larger than specified tolerance, go back to step 2 using the new displacement derived from step 3.

The results can be displayed in two plots. Figure 3 a shows the inelastic demand spectra where total accelerations calculated from the time domain analyses are presented for an LRB isolation system subjected to the $1940 \mathrm{El} \mathrm{Centro}$ record. The straight thin lines labelled with effective periods were calculated from Equation (3b) and the thick lines crossing the inelastic demand spectra for different $\alpha$ values represents the relationship between the true total acceleration and the maximum displacement. The distances from the thick lines to the corresponding thin lines represent the error of Equation (3b), and the small deviations of these two lines for each period suggest acceptable accuracy of the pseudoacceleration assumption. Figure 3 a clearly shows that the best isolation system for this record in terms of minimum acceleration or base shear is an LRB system with $\alpha=0.03$ and an effective isolation period of 3-4s (for a real structure $\alpha=0.05-0.07$ would be used so as to resist wind load). Figure $3 \mathrm{a}$ is particularly useful for selecting an optimal combination at a region where the amplitudes of spectral acceleration and isolator displacement are acceptable, provided that these parameters satisfy all the other relevant code requirements. The demand spectra from a number of records can be plotted in a single graph for the selection of an isolation system with an over-all optimal performance. Note that the maximum displacement of the LRB system for some periods larger than $2.5 \mathrm{~s}$ are larger than the elastic 5\% damped spectral displacement, apparently a result of period shift between the elastic and the yield phases.

The second plot, Figure $3 \mathrm{~b}$, shows the spectral acceleration as a function of displacement index $\gamma$ together with effective period, equivalent viscous damping ratios (at the top of the plot) and restoring force requirement from the UBC 1997 code [9] $(\eta=0.025)$. The thin lines labelled with $\alpha$ values are from Equation (3a). Note that the equivalent damping 
ratio is not used in the calculation of nonlinear response. The broken line labelled with " $\eta=0.025$ " is the code requirement for minimum restoring forces (Equation 9). Isolation systems in the region of the inelastic demand design spectra below this line (as indicated by the two arrows) do not satisfy the code restoring force requirement. A large number of possible cost-effective LRB systems are eliminated for this only moderately strong ground motion.

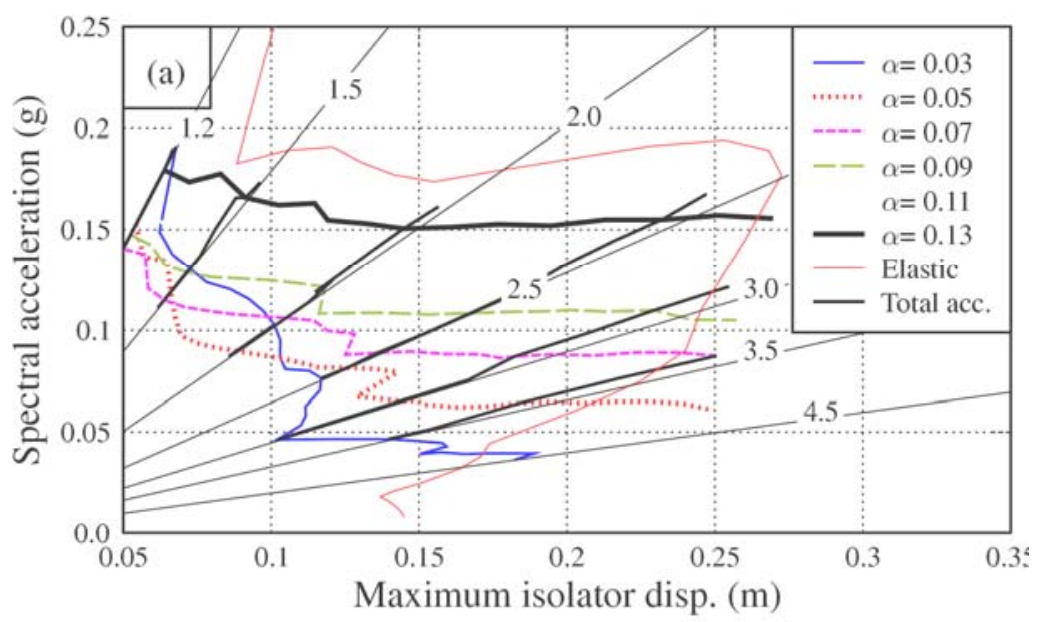

Equivalent damping ratio (\%)

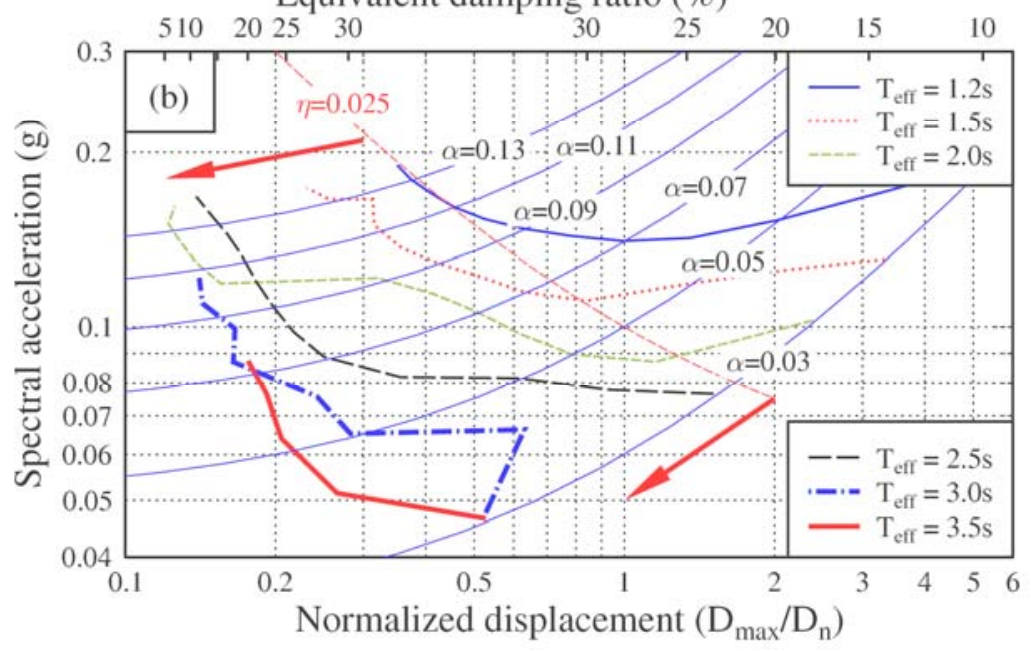

Figure 3. Demand spectra for the NS component of the 1940 El Centro record, (a) demand spectra, and (b) combined plot for spectral accelerations, equivalent damping ratios, and characteristic strength ratio $\alpha=Q_{d} / W$ as functions of displacement index, with arrows indicating the region where LRB systems do not satisfy the restoring force requirement of the 1997 UBC code. Note that the thick solid lines crossing the inelastic demand spectra in Figure 3(a) represent the relationship of the total acceleration and displacement calculated from nonlinear analysis, and they are very close to the thin solid lines labelled with effective periods, suggesting excellent accuracy of Equation $3 a$.

Figure 4 presents the inelastic demand design spectra for the fault-normal component of the Lucerne record from the $M_{W}=$ 7.21992 Landers earthquake. The record had a source distance of $1.5 \mathrm{~km}$, a peak ground acceleration of $0.82 \mathrm{~g}$, and a forward-directivity velocity pulse (Somerville et al [10]) in the fault-normal direction. An LRB system with $\alpha=0.11$ and an effective period of about $4 \mathrm{~s}$ would lead to a spectral acceleration of $0.15 \mathrm{~g}$ and an isolator displacement of 600 $\mathrm{mm}$. If a spectral acceleration of $0.2 \mathrm{~g}$ is allowed, an isolator displacement of $250-300 \mathrm{~mm}$ is required for an isolation system with $\alpha=0.11$ and $T_{\text {eff }}$ about $2.5 \mathrm{~s}$. Figure $4 \mathrm{~b}$ shows that the restoring force requirement (1997 UBC Code [9]) defines a small region where only a few LRB systems with acceptable levels of isolator displacement and spectral acceleration are disallowed. For those records with very large displacement demand at long periods, such as the TCU052 record from the 1999 Chichi earthquake, the restoring requirement has little effect on isolation systems that can be used in practice.

A minimum base shear coefficient does not always lead to selection of an optimal seismic isolation system, as the reduction of floor acceleration is often a prime consideration for using seismic isolation. Skinner et al [11] demonstrated an increase in floor accelerations for high-frequency modes with increasing nonlinearity factor $N L=\pi \xi_{\text {eff }} / 2$. The increase was large when the elastic period of an isolation system was less than about 1.8 times the un-isolated period (Section 4.3.5, Skinner et al [11]). Naeim and Kelly [6] demonstrated that floor accelerations and inter-storey drifts increase with increasing damping ratio after an optimal damping ratio was exceeded (Section 2.3). For LRB isolation systems, these effects are moderate. 

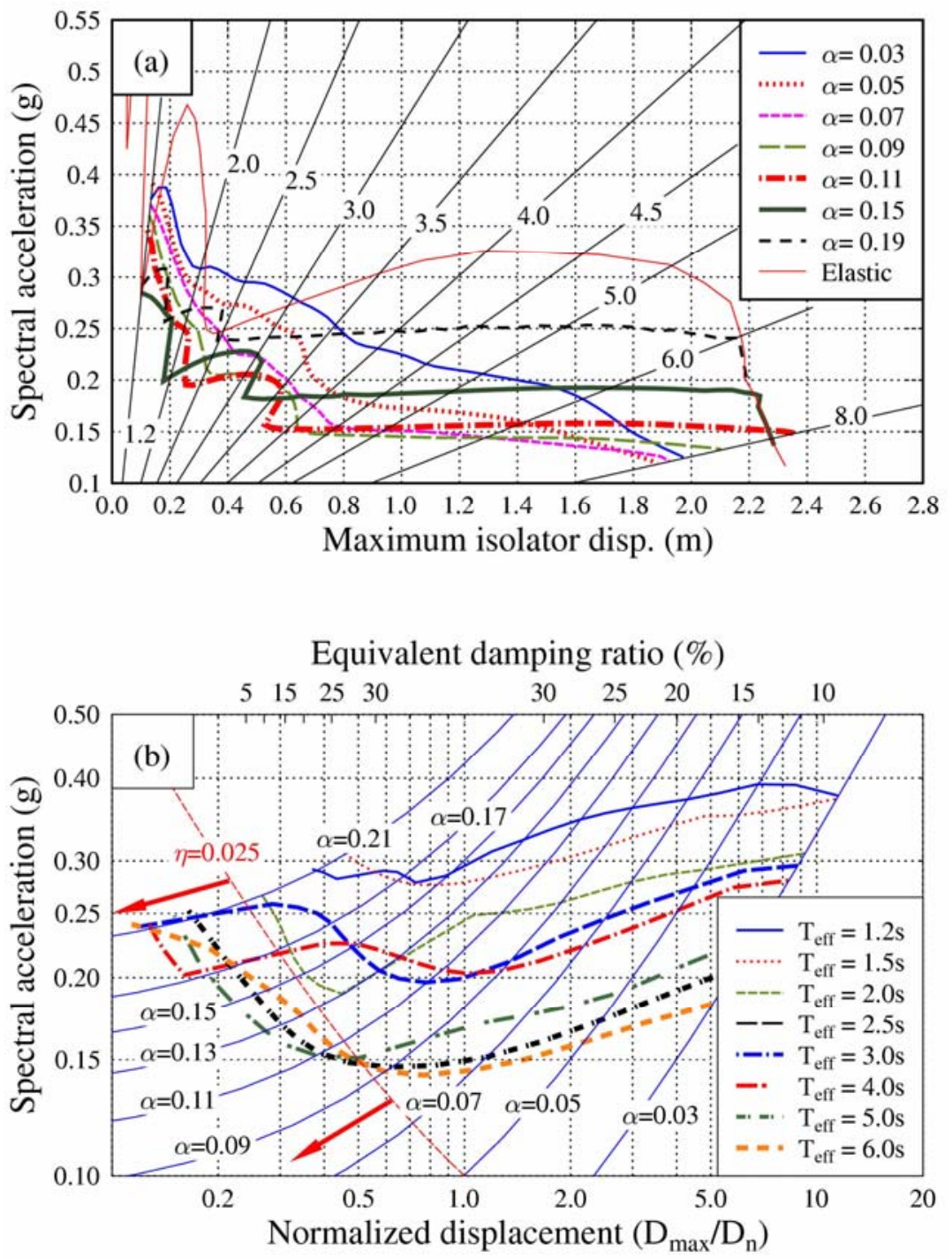

Figure 4. Demand spectra for fault-normal components of records from strike-slip faults with forward-directivity pulses, (a) Lucerne record from the 1992 Landers event, and (b) combined plot for spectral accelerations, equivalent damping ratios, and characteristic strength as functions of displacement index, with arrows indicating the region where LRB systems do not satisfy the restoring force requirement of the 1997 UBC code.

\section{INELASTIC DEMAND SPECTRA FOR NEAR- SOURCE GROUND MOTIONS}

For near-source ground motions, the response of seismicallyisolated structures has been subjected to some debate (Hall et al [2]). We present inelastic demand spectra of near-source ground motions to gain some insight into the design of this type of structure.

\subsection{Forward directivity pulses}

For a near-source ground motion, forward directivity often results in a large velocity pulse in the fault-normal direction (Somerville et al [10]) and such pulses usually result in an excessively large displacement demand for long-period structures. The period of the velocity pulse, or the spectral period of the peak of the velocity spectra in the fault-normal direction, increases with increasing earthquake magnitude. For the fault-parallel direction, this kind of pulse does not usually occur. We present the inelastic demand spectra for the near-source ground motions in the fault-normal direction as this component often controls the design of an isolation system.
Figure 5 presents the inelastic demand design spectra for the fault-normal component of the Array 6 record from the 1979 Imperial Valley earthquake (strike-slip faulting mechanism, $\mathrm{M}_{\mathrm{W}}=6.5$, source distance of $2.5 \mathrm{~km}$ and peak ground acceleration $0.44 \mathrm{~g}$ ). An LRB system with $\alpha=0.09-0.15$ and an effective period of about $2.5 \mathrm{~s}$ would lead to a spectral acceleration about $0.2-0.25 \mathrm{~g}$ and an isolator displacement about $300 \mathrm{~mm}$. If a spectral acceleration of $0.1 \mathrm{~g}$ or less is required, an isolator displacement of $800-850 \mathrm{~mm}$ is required for an isolation system with $\alpha=0.05-0.07$ and $T_{\text {eff }}$ over $6.0 \mathrm{~s}$.

Figure 6 shows the inelastic demand spectra for the faultnormal component of two near-source records from the 1994 Northridge earthquake $\left(M_{W}=6.69\right.$, reverse faulting mechanism). The record obtained at Sylmar County Hospital Parking Lot (at a source distance of $7.2 \mathrm{~km}$ ) has a large displacement demand at about 2-3s spectral periods in the fault-normal direction (Figure 6a). Beyond $2.5 \mathrm{~s}$ periods, the displacement demand reduces quickly with increasing period. An isolation system with $\alpha=0.07-0.09$ and $T_{\text {eff }}=3.5-4 \mathrm{~s}$ leads to a spectral acceleration under $0.15 \mathrm{~g}$ and an isolator displacement of 420-500 mm. Figure $6 \mathrm{~b}$ shows the inelastic demand spectra of the fault-normal component for the 
Rinaldi record (source distance $=6.3 \mathrm{~km}$ ). The base shear coefficient decreases rapidly with increasing period up to $2.5 \mathrm{~s}$, and decreases gradually with rapidly increasing isolator displacement for effective periods beyond $3 \mathrm{~s}$. An isolation system with $\alpha=0.09-0.13$, and $T_{\text {eff }}=3.0 \mathrm{~s}$ results in a spectral acceleration of $0.2 \mathrm{~g}$ and peak isolator displacement about $400 \mathrm{~mm}$, and $0.1 \mathrm{~g}$ for an isolator displacement of $600 \mathrm{~mm}$.

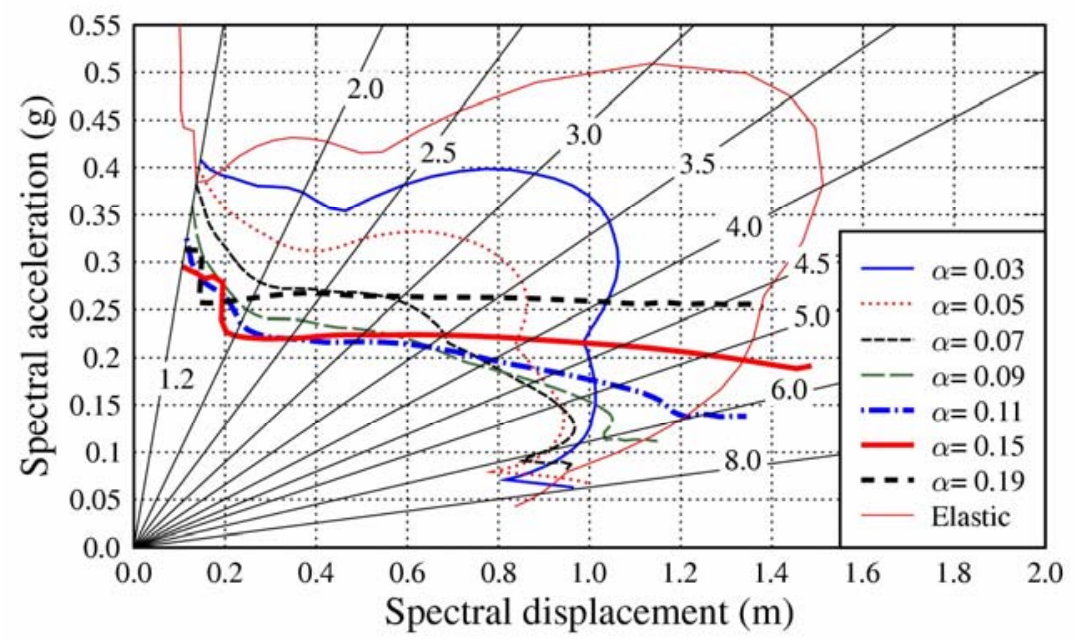

Figure 5. Demand spectra for the fault-normal component of the Array 6 record from the 1979 Imperial Valley earthquake.
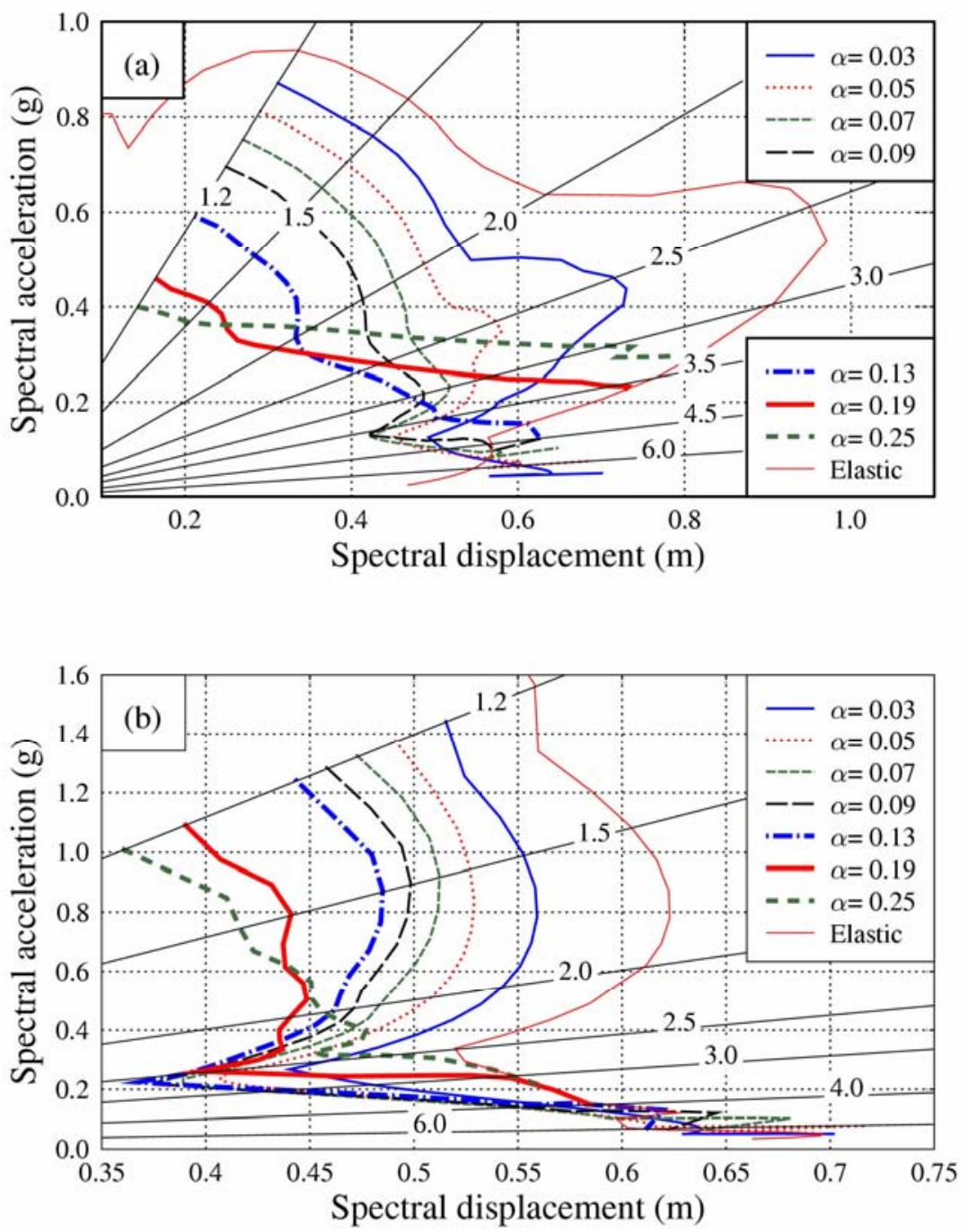

Figure 6. Demand spectra for fault-normal components of records with forward-directivity pulses from the 1994 Northridge event with reverse faulting mechanism, (a) Sylmar County Hospital Parking Lot, and (b) Rinaldi station. 


\subsection{Fault-fling pulses}

Many near-source records were obtained from the 1999 Chichi Taiwan earthquake $\left(M_{W}=7.6\right)$. Those from the northern part of the surface rupture were characterised by very large permanent displacements (fault-fling, Abrahamson [3]) and large velocity pulses. For some records, the ground motions at short and intermediate periods were not very large for such a large magnitude event. We processed the EW and NS components according to the baseline correction method of Boore [12] and then we rotated the components to a direction such that the permanent displacement of one component was nearly zero. This component is referred to as the minimum-fling component. The component in the other perpendicular direction is referred as the maximum-fling component.

Figure $7 \mathrm{a}$ shows the inelastic demand spectra of the maximum-fling component of the TCU052 record with a peak ground acceleration of $0.79 \mathrm{~g}$ and over $7 \mathrm{~m}$ permanent displacement in the north-west direction. For $\alpha=0.03-0.25$, the spectral acceleration for this record is much larger than 1 $\mathrm{g}$ for spectral periods in a range of 1.2-1.8s, and decreases rapidly with increasing effective period in a range of $2-3.5 \mathrm{~s}$. For effective periods beyond $4 \mathrm{~s}$ spectral accelerations are between 0.2 and $0.4 \mathrm{~g}$. The spectral displacement is over $5 \mathrm{~m}$ for $\alpha=0.03$ at the long period end. An optimal seismic isolation system in terms of minimum isolator displacement for this component would have $\alpha=0.13$, an effective period about $3.5 \mathrm{~s}$ with an isolator displacement about $740 \mathrm{~mm}$ and a spectral acceleration of $0.26 \mathrm{~g}$. The same isolation system would have a spectral acceleration $0.2 \mathrm{~g}$ and an isolator displacement about $550 \mathrm{~mm}$ for the minimum component of the record (not shown here).

Figure $7 \mathrm{~b}$ shows the inelastic demand spectra for the maximum-fling component of the TCU068 record. This site was at the northern end of the surface rupture trace and the permanent displacement was over $9 \mathrm{~m}$ in the north-west direction. The peak ground acceleration is $0.67 \mathrm{~g}$ for the maximum-fling component and $0.6 \mathrm{~g}$ for the minimum-fling component. The extremely large displacement demand of this component is evident - between $5 \mathrm{~m}$ and $9 \mathrm{~m}$ at an $8 \mathrm{~s}$ effective period. The optimal isolation system for this record would have $\alpha=0.25$ (further increase in $\alpha$ leads to increasing both spectral acceleration and isolator displacement) and an effective period of $4 \mathrm{~s}$. The spectral accelerations would be $0.33 \mathrm{~g}$ with an isolator displacement of $1,300 \mathrm{~mm}$.

For nearly all near-source records presented here, the 5\% damped elastic spectra are generally larger than those of the seismically-isolated structures for most periods, but can be smaller in some period bands, presumably due to the continuous period shift between the initial elastic and the post yield phases.
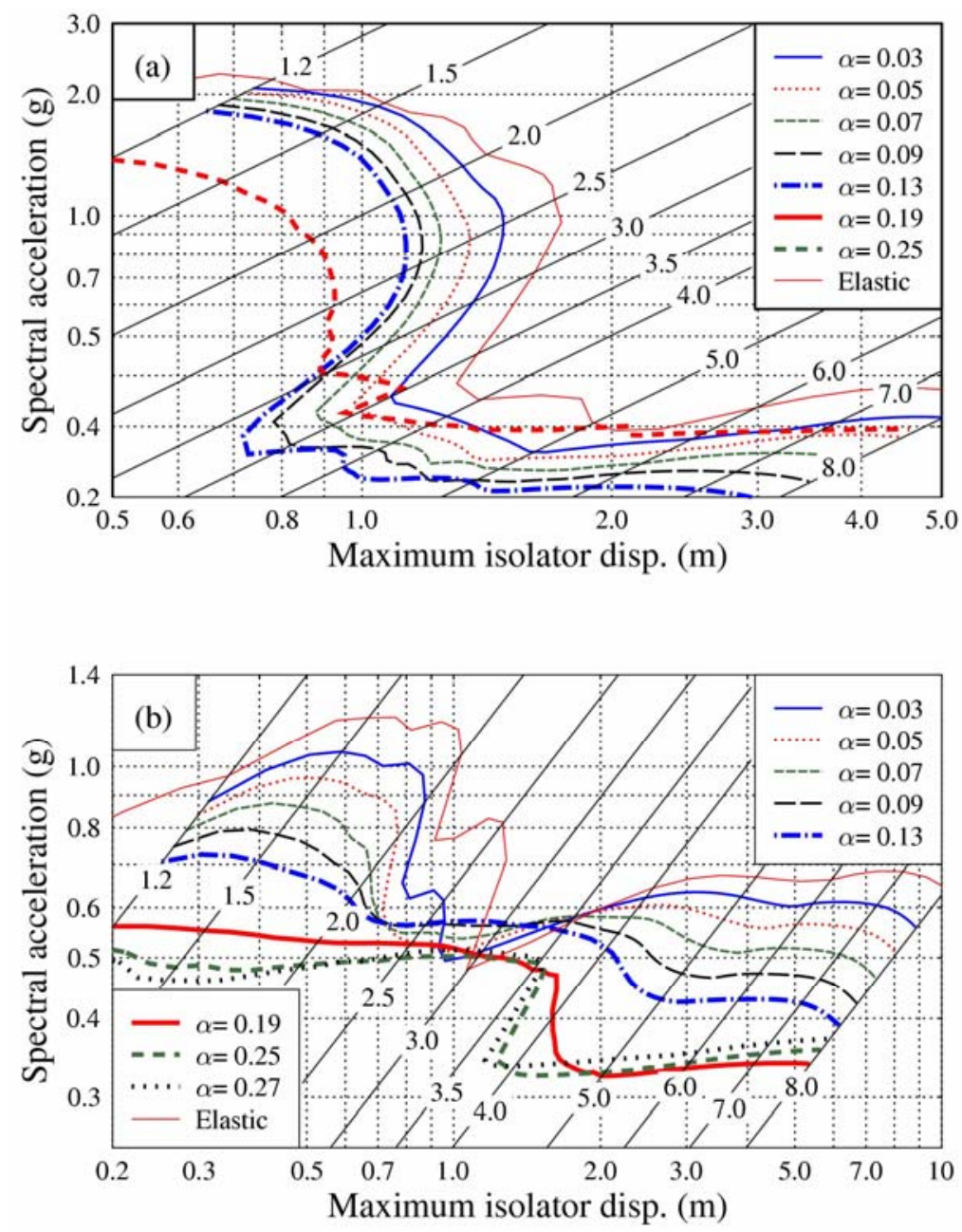

Figure 7. Demand spectra for the maximum-fling components of records with large fault-fling pulses from the 1999 Chichi, Taiwan earthquake, (a) TCU052, (b) TCU068. Note that spectral acceleration of the TCU068 record actually increases with increasing effective period and displacement for $\alpha=0.19-0.25$. 


$\begin{array}{llll}\text { EFFECTS OF } & \text { NEAR-SOURCE RECORDS } \\ \text { FROM DIFFERENT } & \text { TYPES OF } \\ \text { EARTHQUAKES ON } & \text { SEISMICALLY- } \\ \text { ISOLATED STRUCTURES } & \end{array}$

The optimal values of design parameters ( $\alpha$ and $T_{\text {eff }}$ ) vary considerably between different earthquake records, and are not related to either earthquake magnitude or other source parameters in a simple manner. It appears that for nearsource records with forward-directivity pulses, values of $\alpha=$ 0.09-0.13 and $T_{\text {eff }}=3-3.5 \mathrm{~s}$ lead to acceptable levels of isolator displacement (about $500 \mathrm{~mm}$ ) and spectral acceleration (about $0.2 \mathrm{~g}$ or less) for most records that were used. For records with large fault-fling pulses, large values for $\alpha$ would be required in order to achieve feasible isolator displacements.

Figure 8 compares the inelastic demand spectra for the optimal isolation systems selected for five near-source records having either forward-directivity pulses or large fault-fling pulses, together with the inelastic demand spectra for a ductility ratio of $8(\beta=2.5 \%$, calculated by nonlinear time history analysis and presented in effective period calculated from secant stiffness at the peak displacement). For the Lucerne record, the reduction of spectral acceleration by seismic isolation from an un-isolated structure with an effective period less than $1.5 \mathrm{~s}$ is moderate, from $0.25 \mathrm{~g}$ to $0.15 \mathrm{~g}$ with an isolator displacement about $600 \mathrm{~mm}$ (Figure 8a). However, for a short period un-isolated structure the reduction of spectral acceleration by seismic isolation is considerable - by a factor over 2.7. For a structure with a global ductility ratio of 8 , severe damage to the structure or collapse of the structure would occur, while, for a structure with seismic isolation designed for the same ground shaking, the upper structure may experience little inelastic deformation, i.e. may suffer no damage. The isolation system for the Rinaldi record from the 1994 Northridge earthquake reduces spectral acceleration by a factor of 5.5 from $0.81 \mathrm{~g}$ for an un-isolated structure with a ductility ratio of 8 to less than $0.2 \mathrm{~g}$. For the Sylmar record, an isolation system would reduce the spectral accelerations over $0.6 \mathrm{~g}$ for structures with effective periods less than $0.9 \mathrm{~s}$ (elastic period of $0.32 \mathrm{~s}$ ) to about $0.15 \mathrm{~g}$ for an isolator displacement of about $600 \mathrm{~mm}$.

Figure $8 \mathrm{~b}$ shows the inelastic demand spectra for the maximum-fling components of TCU052 and TCU068 records. For the TCU052 record, the reduction of spectral acceleration of the un-isolated structure is significant - from $0.7 \mathrm{~g}$ to $0.2-0.25 \mathrm{~g}$ (note the period shift effect) with an isolator displacement $700-800 \mathrm{~mm}$. For the TCU068 record, the acceleration for the seismically-isolated structure is only marginally reduced from that of the un-isolated structure with a global ductility of 8 and an effective period (un-isolated) less than $3 \mathrm{~s}$ - a similar feature to that for the Lucerne record. However, the large displacement of the isolator $(1,300 \mathrm{~mm})$ will produce a base shear coefficient of 0.33 which may still prevent a carefully designed upper structure from developing excessive inelastic deformation, though seismic isolation appears not to be an effective approach for protecting short period structure from this kind of ground shaking.
The effectiveness of seismic isolation for a structure subjected to the maximum-fling component of the TCU068 record is reduced because of the apparent inability to reduce the base shear coefficient (note that spectral acceleration (just over $0.3 \mathrm{~g}$ ) does not decrease with increasing isolator displacement, Figure $7 b$ ). The conventional structure with an elastic period less than $1 \mathrm{~s}$ (i.e., a less than $2 \mathrm{~s}$ effective period) may respond reasonably well to this record judged by spectral displacement demand at short and intermediate periods. Also at long periods, the base shear of an un-isolated structure can be smaller than that of an isolated structure. It appears that seismic isolation may not be the best approach for this particular type of ground motion. However, further investigation is still required for assessing the effectiveness of seismic isolation, as similar level of spectral displacements and spectral acceleration may lead to unacceptably large inter-storey drift for an un-isolated structure while acceptable inter-storey drift may be achieved for a seismically isolated structure.

\section{CONCLUSIONS}

The following conclusions can be reached in the present study,

1) Inelastic demand spectra were developed for seismic isolation systems with bi-linear force-displacement hysteresis loops. Using a damping ratio of $5 \%$ or less calculated from the initial stiffness of lead-rubber bearing, pseudo-acceleration approximates the true total acceleration reasonably well. The use of a damping coefficient that is calculated from either the post-yield stiffness or the tangent stiffness minimizes errors caused by the use of pseudo-acceleration rather than true total accelerations in the inelastic demand spectra;

2) Because, in the construction of inelastic demand spectra, the true acceleration and the spectral displacement of bilinear systems were calculated by fully-nonlinear analysis, the errors associated with the substitute elastic structure, may be eliminated;

3) The inelastic demand spectrum formulated for seismic isolation may be an excellent tool for visual selection of optimal isolation systems.

4) Using a normalized displacement means that maximum acceleration, equivalent damping ratio, effective period, the ratio of characteristic strength over the weight of the structure supported by the isolator and the restoring force requirement in the 1997 UBC code can all be plotted on a single plot for easy visual selection of design parameters; and

5) Inelastic demand spectra for a number of near-source records with forward directivity or fault-fling pulses are presented. Lead-rubber bearing isolation systems are effective in reducing base shear with acceptable isolator displacement for all near-source records that we analysed but except for the maximum-fling component of the TCU068 record from the 1999 Chichi Taiwan earthquake. 

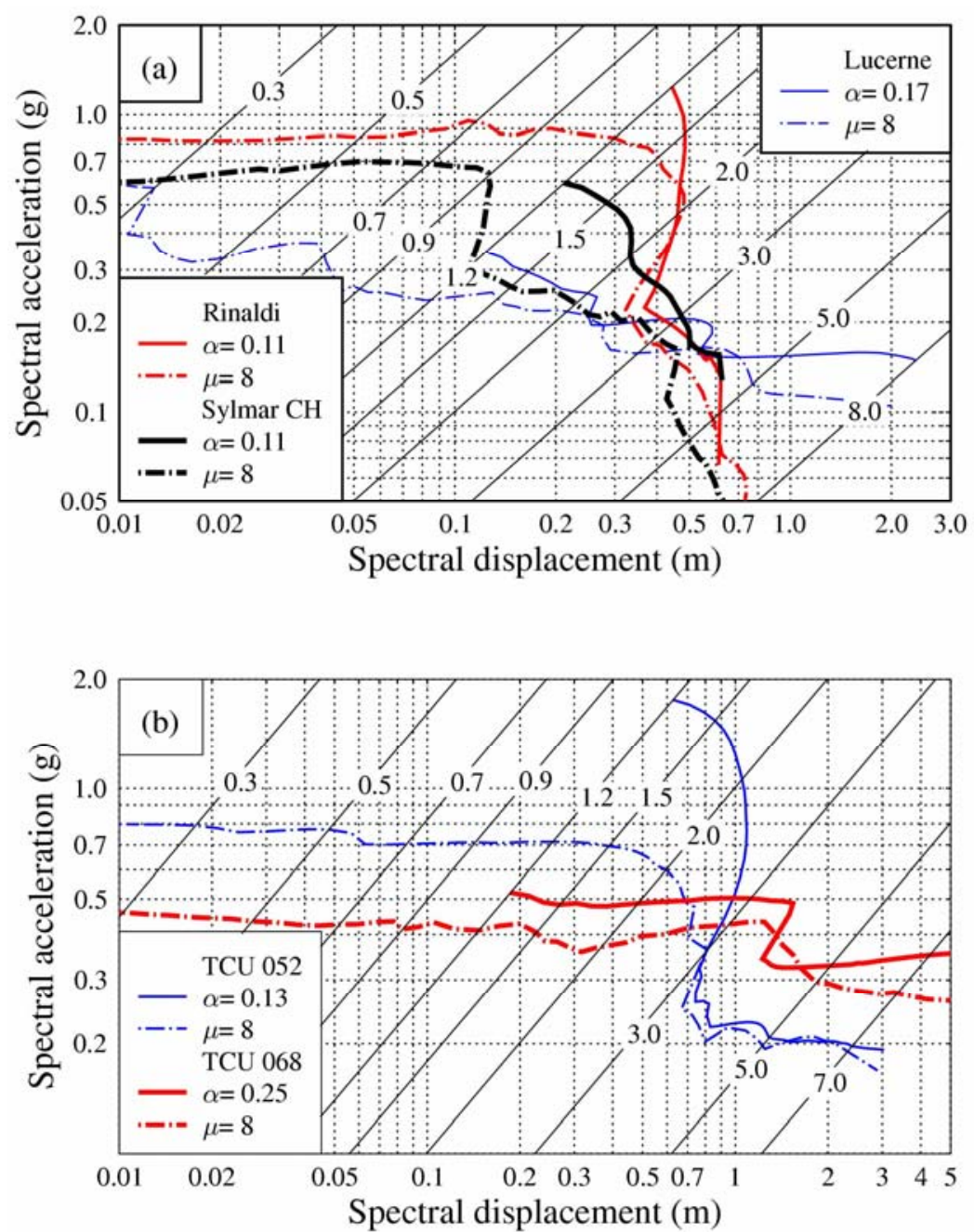

Figure 8. Comparison of responses for seismically-isolated structures and conventional structures under excitation of nearsource records, (a) fault-normal component with forward-directivity effects, (b) maximum-fling components of TCU052 and TCU068 records.

\section{ACKNOWLEDGEMENT}

The authors wish to thank Jim Cousins and Graeme McVerry for their review of the manuscript. We also like to thank Trevor Kelly for his invaluable review comments. This study is supported in part by the Foundation for Research Science and Technology of New Zealand, Contract numbers C05X0208 and C05X0301.

\section{REFERENCES}

1. AASHTO, 1991 and 1999 Guide specifications for seismic isolation design, American Association of State Highway transportation Officials, Washington D.C.

2. Hall, J.F., Heaton, T.H., Halling, M.W. and Wald, D.J., (1995). Near-source ground motion and its effects on flexible buildings, Earthquake Spectra, 11 (4): 569-606.

3. Abrahamson, N. (2001). Incorporating effects of near fault tectonic deformation into design ground motions. A presentation sponsored by the EERI Visiting Professional Program, hosted by the University at
Buffalo, 26 October 2001, http://civil.eng.buffalo.edu/ webcast/abrahamson/presentation files/frame.htm

4. Ramallo, J.C., Johnson, E.A. and Spencer Jr., B.F. (2002). "Smart"' Base Isolation Systems, Journal of Engineering Mechanics, ASCE, 128 (10): 1088-1099.

5. Jangid, R. S. and Kelly, J. M. (2001). Base isolation for near-fault motions, Earthquake Engineering and Structural Dynamics, 30 (5): 691-707.

6. Naeim, F. and Kelly, J.M. (1999). Design of seismic isolated structures, from theory to practice, John Wiley and Sons Ltd, New York, USA.

7. Kelly, T.E. (2001). Base isolation of structures Design guidelines, Holmes Consulting Group http://www.holmesgroup.com/

8. Zhao, J.X. (2004). Response of seismically isolated buildings with buffers subjected to near-source ground motions and possible alternative isolation systems, Bulletin of the New Zealand Society for Earthquake Engineering, Vol. 37 (3): 111-133. 
9. International Conference of Building Officials 1997, Earthquake regulations for seismic-isolated structures, Uniform Building Code, Appendix Chapter 16, Whittier, CA.

10. Somerville, P.G., Smith, N.F., Graves, R.W. and Abrahamson, N.A. (1997). Modification of empirical strong ground attenuation relations to include the amplitude and duration effects of rupture directivity, Seismological Research Letters, 68 (1): 199-222.
11. Skinner, R.I., Robinson, W.H. and McVerry, G.H. (1993). An introduction to seismic isolation, John Wiley and Sons Ltd, West Sussex, England.

12. Boore, D. M., (2001). Effect of baseline corrections on displacement and response spectra for several recordings of the 1999 Chi-chi, Taiwan, earthquake. Bulletin or Seismological Society of America, 91 (5) 1199-1221. 